\title{
ACUTE EXACERBATION OF IDIOPATHIC PULMONARY FIBROSIS AFTER INHALATION OF A WATER REPELLENT
}

\section{DAVID BENNETT ${ }^{1}$, ELENA BARGAGLI ${ }^{1}$, ROSA METELLA REFINI ${ }^{1}$, MARIA PIERONI ${ }^{1}$, ANTONELLA FOSSI ${ }^{1}$, RICCARDO ROMEO ${ }^{2}$, LUCA VOLTERRANI ${ }^{3}$, MARIA ANTONIETTA MAZZEI ${ }^{3}$, and PAOLA ROTTOLI ${ }^{1}$}

University of Siena, Siena, Italy

Department of Medical and Surgical Sciences and Neurosciences

${ }^{1}$ Respiratory Diseases Unit

${ }^{2}$ Occupational Medicine Unit

${ }^{3}$ Diagnostic Imaging Unit

\begin{abstract}
The natural course of idiopathic pulmonary fibrosis (IPF) is unpredictable at the time of diagnosis. Some patients may experience episodes of acute respiratory worsening that have been termed acute exacerbations. A 58-year-old male was admitted to our Emergency Department due to progressive and intense dyspnea and dry cough after accidental inhalation of waterproof's vapor containing siloxanes. Chest high resolution computed tomography (HRCT) scan showed diffuse and bilateral ground glass attenuation, basal predominant reticular abnormalities and subpleural honeycombing. The patient didn't know that he suffered from IPF and siloxanes' inhalation triggered an acute exacerbation of his disease. Clinical course after the inhalation was aggressive and, despite steroids and cyclophosphamide therapy, the patient died 3 months after due to a respiratory failure. Inhalation of water repellents has been associated with an acute onset of respiratory symptoms and acute lung injury; usually, however, the prognosis is commonly good with a complete recovery. Our case is an example of an extremely negative reaction probably because of pre-existing and misdiagnosed IPF. Currently, no literature concerning water repellent inhalation as a trigger of acute exacerbation of IPF is available.
\end{abstract}

Key words:

Siloxanes, Acute exacerbation, Idiopathic pulmonary fibrosis, Water proof inhalation, Occupational exposure, Chemical hazard

\section{INTRODUCTION}

A 58-year-old male smoker (60 pack/year) was admitted to the Emergency Department of the Azienda Ospedaliera Universitaria Senese "Le Scotte," Siena, Italy due to progressive and intense dyspnea, and dry cough after accidental exposure to siloxane-based waterproof vapor. During performing work as a tiler and with no protective equipment the patient experienced massive inhalation of a water repellent in a closed environment. The siloxanebased waterproof was utilized to isolate the ground after laying the tiles.

At the hospital admission, the patient had fever $\left(38^{\circ} \mathrm{C}\right)$, intense dyspnea, dry cough and respiratory distress (respiratory rate -30 breaths per min, peripheral oxygen

Received: September 13, 2014. Accepted: December 18, 2014.

Corresponding author: D. Bennett, University of Siena, Department of Medical and Surgical Sciences and Neurosciences, Respiratory Diseases Unit, "Le Scotte" Hospital, Viale Bracci 16, 53100 Siena, Italy (e-mail: david.btt@gmail.com). 
saturation $-82 \%$, heart rate -115 beats per min, blood pressure $-115 / 80 \mathrm{~mm} \mathrm{Hg}$ ). Arterial blood gas analysis showed severe hypoxemia and respiratory alkalosis $\left(\mathrm{pH}=7.5\right.$, partial pressure of carbon dioxide $\left(\mathrm{pCO}_{2}\right)-$ $31 \mathrm{~mm} \mathrm{Hg}$, partial pressure of oxygene $\left(\mathrm{pO}_{2}\right)-39 \mathrm{~mm} \mathrm{Hg}$, bicarbonate $\left.\left(\mathrm{HCO}_{3}^{-}\right)-25.5 \mathrm{mmol} / \mathrm{l}\right)$ so, oxygen supplementation was started. Routine blood examination showed leukocytosis (white blood cells (WBC) - 14130 cells/ $\mu$ l), but $\mathrm{C}$-reactive protein was negative. No other alterations were observed. Chest auscultation revealed diffusely reduced vesicular murmur and basal crackles; digital clubbing was also evident. Chest high-resolution computed tomography (HRCT) scan reported diffuse and bilateral ground glass attenuation, superimposed to reticular abnormalities with basal and subpleural honeycombing - all indicative of usual interstitial pneumonia (UIP) pattern (Photo 1). The patient reported exertional dyspnea and dry cough during the last 8-10 months, but he did not perform any medical examinations. He denied arthralgia or other connective tissue diseases' symptoms. Serological screening for autoantibodies was negative.

Clinical conditions improved 48-72 h after admission with a low dose of IV steroids, so bronchoscopy with bronchoalveolar lavage (BAL) was performed. Bronchoalveolar lavage cellular composition revealed: macrophages $-80 \%$, lymphocytes $-3 \%$, neutrophils $-9 \%$, eosinophils $-8 \%$, and lymphocytes CD4/CD8 ratio -0.95 . Erythrocytes, foamy macrophages and some anthracotic and emosiderin-laden macrophages were also present. Bronchoalveolar lavage microbiological cultures for aerobic and anaerobic bacteria, fungi and polymerase chain reaction (PCR) for common respiratory viruses were negative. Despite severe gas exchange impairment, which required oxygen-therapy, pulmonary function tests revealed mild restrictive abnormalities (forced vital capacity (FVC) $-72 \%$ of predicted normal value (pred.), forced expiratory volume in $1 \mathrm{~s}\left(\mathrm{FEV}_{1}\right)-70 \%$ pred., forced expiratory volume in $1 \mathrm{~s} /$ vital capacity $\left(\mathrm{FEV}_{1} /\right.$ VC) -0.77 , total lung capacity (TLC) $-81 \%$ pred.). Diffusing capacity of lung for carbon monoxide (DLCO) was not performed because the patient was on the oxygen-therapy.

Because of the initial amelioration of respiratory conditions by the use of steroids, a high dose of pulsed intravenous metilprednisolone (10 $\mathrm{mg} / \mathrm{kg}$ per 3 days) was administered. The patient's respiratory conditions seemed to
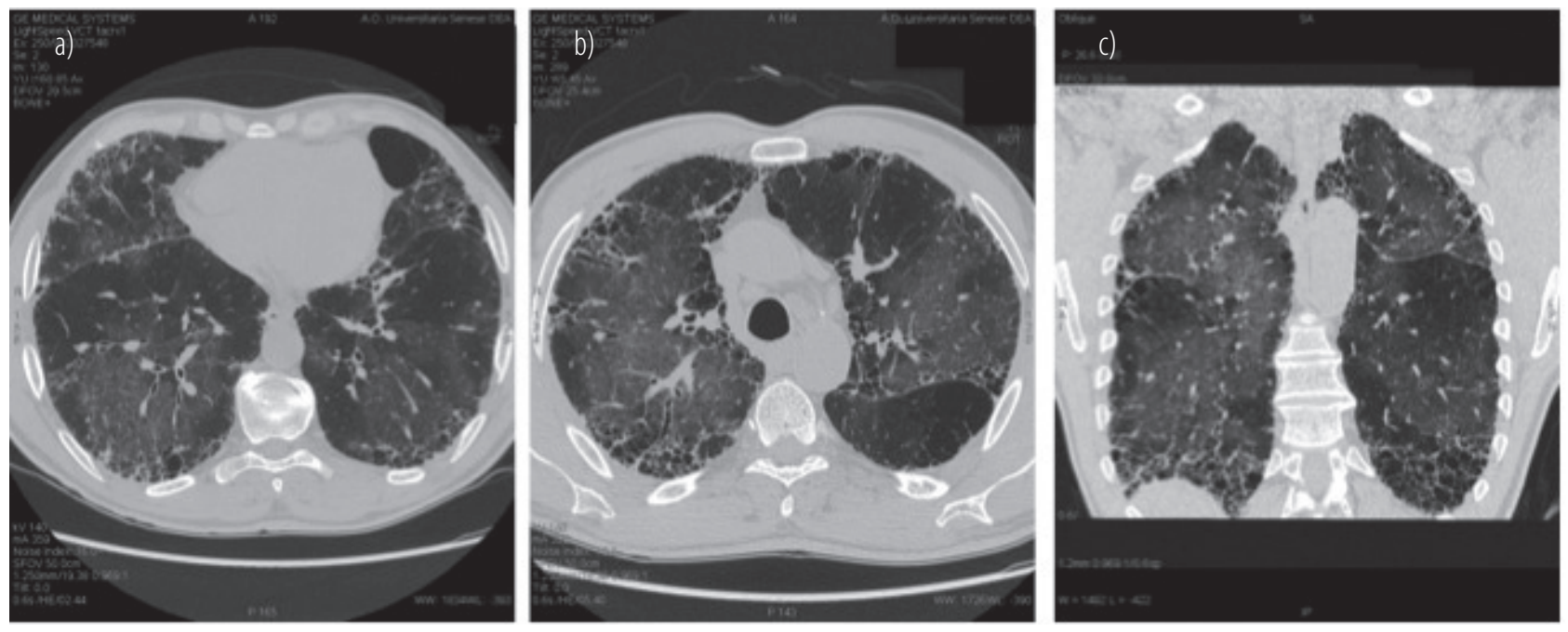

Photo 1. Chest high-resolution computed tomography showing diffuse and bilateral ground glass attenuation, reticular abnormalities with basal and subpleural honeycombing at clinical presentation: a) and b) transverse sections, c) coronal reconstruction 

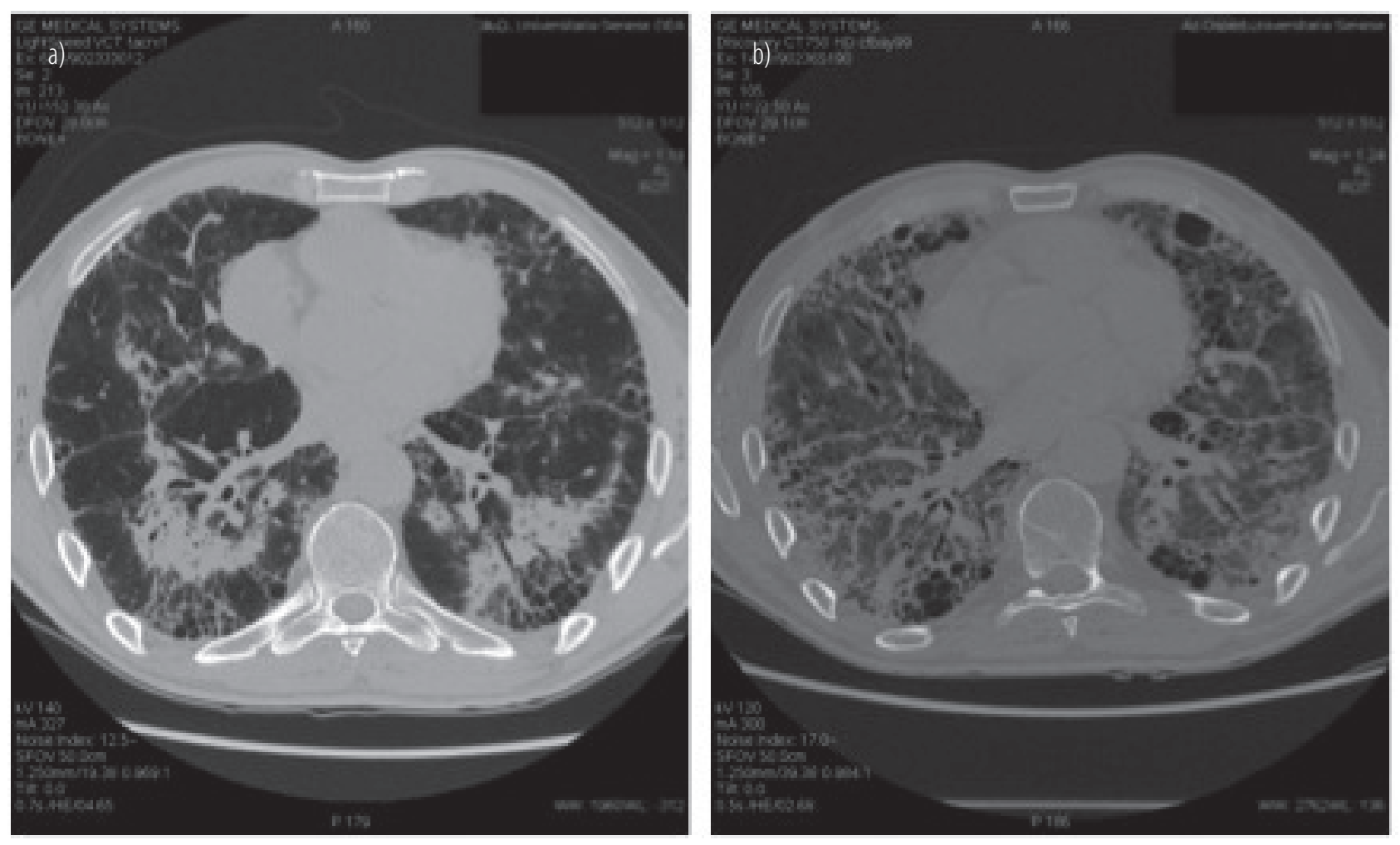

a) Areas of peribronchovascular consolidations where ground glass was previously observed.

b) A significant increment of fibrotic pulmonary changes is evident, in particular intralobular ground glass, reticular abnormalities and the increased extent of honeycombing areas.

Photo 2. Chest high-resolution computed tomography a) 2 weeks after the inhalation, b) 5 weeks after the inhalation

have stabilized and 15 days after the inhalation another chest HRCT was performed. This time it showed numerous areas of peribronchovascular consolidations where ground glass was previously observed (Photo 2a). The patient was discharged with a diagnosis of acute exacerbation of subclinical idiopathic pulmonary fibrosis (IPF) after inhalation of siloxanes for professional reasons.

Unfortunately, 5 weeks later the patient was re-admitted due to a severe decline of respiratory conditions (FVC was now $42 \%$ pred.). Chest HRCT showed a significant increment of fibrotic pulmonary changes, in particular intralobular ground glass, reticular abnormalities and the increased extent of honeycombing areas (Photo 2b). Intravenous cyclophosphamide (500 $\mathrm{mg} / \mathrm{m}^{2}$ body surface) was administered as a rescue therapy. Despite the treatment, the patient's respiratory conditions continued to deteriorate and 87 days after the aerosolized water repellent's inhalation, the patient died from a respiratory failure.

\section{DISCUSSION}

Water repellent sprays contain a mixture of solvents, propellants and a hydro repellent agent, such as fluorocarbons or silicon resins. Our patient inhaled a solution containing siloxane oligomers emulsified in water. Siloxanes are chemical compounds composed of silicon, oxygen and alkane $\left(\mathrm{R}_{2} \mathrm{SiO}\right.$, where $\mathrm{R}$ is a hydrogen atom or a hydrocarbon group). Polymerized siloxanes with organic side chains are commonly known as silicones.

No literature regarding effects of the water repellents' inhalation in IPF is available, although negative pulmonary 
effects of water repellents' inhalation have been reported [1-9]. Our case showed an extremely negative and aggressive impact, probably because of the pre-existing and misdiagnosed IPF.

The natural course of IPF is unpredictable at the time of diagnosis [10-13]. Any patient may experience episodes of acute respiratory worsening that have been termed acute exacerbations (AE-IPF) [10]. It is presently unclear if these conditions are simply manifestations of unidentified respiratory complications (such as pulmonary emboli, respiratory infection) contributing to an acute worsening in a patient with IPF or if they represent an inherent acceleration in the pathobiological processes involved in IPF [10]. There is no consensus regarding approach to the diagnosis of those events. In 2007 specific criteria based on worsening of respiratory conditions, radiological findings and exclusion of other causes have been proposed [11]. At chest HRCT typically AE-IPF appears with multifocal and diffuse ground glass superimposed on the basal subpleural reticular abnormality, traction bronchiectasis, and honeycomb change typical of usual interstitial pneumonia (UIP) pattern [11]. In our case radiological findings perfectly matched this description. In some cases, just as in the case of our patient, the acute exacerbation could represent a starting point that leads to the diagnosis of IPF [13].

Inhaled chemical compounds such as water repellents may trigger AE-IPF and this event could be the 1st manifestation of this chronic and severe lung disorder. In the presented case, the initial and mild amelioration of respiratory conditions may be ascribable to the so called "polymer-fune fever syndrome," as like in fluorocarbons' inhalation, which in most cases resolves within a day or two $[6,8,9]$. In the case of our patient, inhalation of siloxanes simultaneously triggered an acute exacerbation of idiopathic pulmonary fibrosis with diffuse alveolar damage bringing the patient to death.
Pathogenesis of the waterproof-induced pulmonary damage is not clear, especially in the patients with interstitial lung diseases. It can directly act on the alveolar surface causing surfactant alterations and alveolar collapse [9]. A direct toxic effect has been demonstrated on alveolar cells [14] and naturally, it is strictly related to the aerosolized particles size [15]. Waterproof substances may alter gas exchange at the alveolar level modifying the alveolar surface tension and facilitating cellular apoptosis [9]. Usually, the prognosis of toxic alveolitis induced by fluorochemical-based compounds is good with a complete recovery in a few weeks even without a therapy, or just with a low dose of oral steroids [6,9]. In our patient with IPF, the severe and progressive clinical conditions prompted us to establish treatment with a high dose of intra-venous corticosteroid and cyclophosphamide. Clear recommendations on the therapy of acute exacerbations of IPF are still unavailable, but the use of steroids and cyclophosphamide has been reported before [10,11].

\section{CONCLUSIONS}

In conclusion, our case report suggests potential more severe negative respiratory effects of waterproof substances containing siloxanes in the patients with chronic respiratory diseases. Clinical and radiological findings in a patient with IPF, professionally exposed to this chemical compound, are herein firstly reported, suggesting that this kind of inhalation may induce acute exacerbation of IPF.

\section{REFERENCES}

1. Thibaut G, Wylomanski JL, Laroche D. [Pulmonary intoxication by accidental inhalation of a household aerosol water repellent]. Toxicol Eur Res. 1983 Mar;5(2):81-4. French.

2. Testud F, Gabrielle L, Paquin ML, Descotes J. [Acute alveolitis after using a waterproofing aerosol: Apropos of 2 cases]. Rev Med Interne. 1998 Apr;19(4):262-4, http://dx.doi. org/10.1016/S0248-8663(97)89328-9. French. 
3. Caron MF, White CM. Pneumonitis following inhalation of a commercially available water repellent. J Toxicol Clin Toxicol. 2001;39(2):179-80, http://dx.doi.org/10.1081/CLT100103838 .

4. Bonte F, Rudolphus A, Tan KY, Aerts JG. [Severe respiratory symptoms following the use of waterproofing sprays]. Ned Tijdschr Geneeskd. 2003 Jun 14;147(24):1185-8. Dutch.

5. Tagawa A, Ikehara K, Tsuburai T, Nishiyama H, Miyazawa N, Hashiba T, et al. [Acute lung injury caused by inhalation of waterproofing spray]. Nihon Kokyuki Gakkai Zasshi. 2003 Feb;41(2):123-6. Japanese.

6. Epping G, van Baarlen J, van der Valk PD. Toxic alveolitis after inhalation of a water repellent. Int J Occup Med Environ Health. 2011 Dec;24(4):409-13, http://dx.doi.org/10. 2478/s13382-011-0038-7.

7. Daubert GP, Spiller H, Crouch BI, Seiferta SA, Simone KE, Smolinske SC. Pulmonary toxicity following exposure to waterproofing grout sealer. J Med Toxicol. 2009 Sep;5(3): 125-9, http://dx.doi.org/10.1007/BF03161222.

8. Centers for Disease Control (CDC). Polymer-fume fever associated with cigarette smoking and the use of tetrafluoroethylene - Mississippi. MMWR Morb Mortal Wkly Rep. 1987 Aug 14;36(31):515-6,521-2.

9. Vernez D, Bruzzi R, Kupferschmidt H, De-Batz A, Droz P, Lazor R. Acute respiratory syndrome after inhalation of waterproofing sprays: A posteriori exposure-response assessment in 102 cases. J Occup Environ Hyg. 2006 May; 3(5):250-61, http://dx.doi.org/10.1080/15459620600628845.
10. Raghu G, Collard HR, Egan JJ, Martinez FL, Behr J, Brown KK, et al. An official ATS/ERS/JRS/ALAT statement: Idiopathic pulmonary fibrosis: Evidence-based guidelines for diagnosis and management. Am J Respir Crit Care Med. 2011 Mar 15;183(6):788-824, http://dx.doi. org/10.1164/rccm.2009-040GL.

11. Collard HR, Moore BB, Flaherty KR, Brown KK, Kaner RJ, King TE Jr, et al. Acute exacerbations of idiopathic pulmonary fibrosis. Am J Respir Crit Care Med. 2007 Oct 1; 176(7):636-43, http://dx.doi.org/10.1164/rccm.200703-463PP.

12. Ambrosini V, Cancellieri A, Chilosi M, Zompatori M, Trisoloni R, Saragoni L, et al. Acute exacerbation of idiopathic pulmonary fibrosis: Report of a series. Eur Respir J. 2003 Nov;22(5):821-6, http://dx.doi.org/10.1183/ 09031936.03.00022703.

13. Sakamoto K, Taniguchi H, Kondoh Y, Ono K, Hasegawa Y, Kitaichi M. Acute exacerbation of idiopathic pulmonary fibrosis as the initial presentation of the disease. Eur Respir Rev 2009;18(112):129-32, http://dx.doi. org/10.1183/09059180.00000409.

14. Hubbs AF, Castranova V, Ma JY, Frazer DG, Siegel PD, Ducatman BS, et al. Acute lung injury induced by a commercial leather conditioner. Toxicol Appl Pharmacol. 1997 Mar;143(1):37-46, http://dx.doi.org/10.1006/taap.1996.8053.

15. Yamashita M, Tanaka J, Yamashita M, Hirai H, Suzuki M, Kajigaya H. Mist particle diameters are related to the toxicity of waterproofing sprays: Comparison between toxic and non-toxic products. Vet Hum Toxicol. 1997 Apr;39(2):71-4.

This work is available in Open Access model and licensed under a Creative Commons Attribution-NonCommercial 3.0 Poland License - http://creativecommons.org/ licenses/by-nc/3.0/pl/deed.en. 